\title{
Statistical Practices of Safety Monitoring: An Industry Survey
}

Therapeutic Innovation \& Regulatory Science 2019, Vol. 53(3) 293-300 (c) The Author(s) 2018 Article reuse guidelines: sagepub.com/journals-permissions DOI: $10.1177 / 2168479018779973$ tirs.sagepub.com

\author{
Michael W. Colopy, PhD' ${ }^{\mathbb{D}}$, Robert Gordon, $\mathbf{M S}^{2}$, \\ Faiz Ahmad, MPhil, MS ${ }^{3}$, William W. Wang, PhD ${ }^{4}$, \\ Susan P. Duke, $\mathrm{MS}^{5}$, and Greg Ball, $\mathrm{PhD}^{4}$
}

\begin{abstract}
The Biopharmaceutical Section of the American Statistical Association (ASA) formed a Safety Monitoring Working Group to strengthen collaborations between biostatisticians and safety scientists. The task began by surveying current needs and practices regarding available statistical safety tools and methods, regulatory guidance, and processes needed to support their implementation. The goal is for biostatisticians to become fully engaged safety team members by having the necessary safety skill set including appropriate methodology, regulatory guidance and access to appropriate tools. In this publication, we will discuss our survey results that reveal current practices at 22 pharmaceutical companies and demonstrate how the survey instrument can be used to map an action plan for meeting the demand for improved quantitative safety monitoring.
\end{abstract}

\section{Keywords}

safety monitoring, regulatory guidance, interviews, survey, biostatistician

\section{Motivation}

For the safety for our patients, as well as for regulatory compliance, improved safety monitoring is becoming increasingly important. The 2010 FDA Investigational New Drug (IND) Safety Reporting Final Rule, ${ }^{1}$ the 2012 final guidance, ${ }^{2}$ and the 2015 draft guidance ${ }^{3}$ state that sponsors should notify the agency and participating investigators of only those adverse events where "there is a reasonable possibility that the drug caused the adverse event." Within the 2012 guidance the agency offers numerous examples, suggesting a causal relationship and references 21 CFR 312.32 (c)(1)(i) for more details. This effort is intended to minimize uninformative reports and "noise" in the data, which has the possibility of masking safety signals. Compliance with this guidance would require a collaborative approach between safety scientists and biostatisticians to establish a quantitative framework to measure the true safety signals. Biostatisticians need to help their drug safety department move from submitting all safety reports to only those where there is a reasonable possibility that the drug caused the event. Working as a team to conduct earlier aggregated analyses and minimize the submission of uninformative and uninterpretable reports would be a valuable contribution by biostatisticians.

For late-stage biostatisticians, this may require a paradigm shift in thinking from formally testing drug efficacy to exploring drug safety. An evolving set of analyses are needed to fully characterize the safety profile of the product (ongoing aggregate safety evaluation) and help prepare for safety assessments presented in safety-related documents (scientific evaluation of safety data). Decision making based on accumulating evidence and clinical judgment is different for unplanned safety events than decision rules for primary efficacy endpoints. In response, the Biopharmaceutical Section of the American Statistical Association (ASA) formed a working group to identify opportunities for biostatisticians to work with their fellow safety scientists.

\section{Background}

To gauge current use of the safety monitoring toolset in clinical trials, the working group conducted a survey in 2016 (see Supplemental Appendix). The group first drafted a 40-question survey and administered it to 14 companies represented by the group. After reviewing the results, the open-ended questions

\footnotetext{
'Statistical Sciences \& Innovation, UCB BioSciences Inc, Research Triangle Park, NC, USA

${ }^{2}$ Statistics and Decision Sciences, Janssen Research \& Development LLC, Spring House, PA, USA

${ }^{3}$ US Biostatistics, Galderma R\&D, Fort Worth, TX, USA

${ }^{4}$ Biostatistics and Research Decision Sciences, Merck Research Laboratories, North Wales, PA, USA

${ }^{5}$ Department of Statistics, AbbVie, North Chicago, IL, USA
}

Submitted 3-Apr-2018; accepted I-May-20I8

Corresponding Author:

Michael W. Colopy, PhD, Statistical Sciences \& Innovation, UCB BioSciences, PO Box I 10167, Research Triangle Park, NC 27709, USA.

Email: michael.colopy@ucb.com 
Table I. Company Description.

\begin{tabular}{lc}
\hline & Percentage \\
\hline No. of employees & \\
Very small $(<1 \mathrm{k})$ & 4 \\
Small $(<10 \mathrm{k})$ & 17 \\
Medium $(<50 \mathrm{k})$ & 33 \\
Large $(<100 \mathrm{k})$ & 21 \\
Very large $(\geq 100 \mathrm{k})$ & 25 \\
No. of clinical trial biostatisticians & \\
$1-9$ & 4 \\
$10-19$ & 4 \\
$20-49$ & 17 \\
$50-99$ & 31 \\
$\geq 100$ & 44 \\
No. of safety biostatisticians & \\
0 & 50 \\
1 & 13 \\
2 & 0 \\
$3-5$ & 8 \\
$6-9$ & 13 \\
$\geq 10$ & 16 \\
\hline
\end{tabular}

Table 2. How Do Biostatisticians Support the Safety Management Team?

\begin{tabular}{lc}
\hline Level of Support & Percentage of Responses \\
\hline I. No support & 5 \\
2. Document reviewer & 64 \\
3. Internal statistical consultant & 64 \\
4. Collaborator & 68 \\
5. Core team member & 50 \\
\hline
\end{tabular}

were changed to multiple-choice questions, and the survey was reduced to 17 well-focused questions that were easier to summarize and interpret. Biostatisticians paired with clinical safety scientists representing 30 biopharmaceutical companies were invited to participate, of which $22(73 \%)$ responded. To protect the anonymity, the company name and responder(s) name were not collected.

The participating companies ranged in size from less than 1000 to over 100,000 employees and covered all therapeutic areas surveyed. The number of biostatisticians ranged from less than 10 to over 100 per company. Although only 2 of the larger companies had a separate safety statistics group, half of all companies had 1 or more biostatisticians dedicated to safety statistics (Table 1).

While biostatisticians serve as document reviewers, consultants, and collaborators to their safety management team, only half of the companies responded that biostatisticians serve as core safety team members (Table 2 ).

To recommend how statistical groups can play a more meaningful and collaborative role in monitoring drug safety, we focused on 3 key areas of our survey: scientific engagement, visual and analytic tools, and effective processes.

\section{Cross-Disciplinary Scientific Engagement}

Safety physicians often conduct qualitative reviews of case reports, looking at individual or small clusters of events. This has required little or no statistical input. With the increasing emphasis on aggregate reviews of safety data, biostatisticians need to help cross-disciplinary safety management teams to think more quantitatively. The type of statistical support will depend on the type of analyses required and who is currently conducting the analyses.

As shown in Table 3, clinical trial biostatisticians heavily contribute in most aspects of safety analysis except analysis of unblinded data from ongoing trials and spontaneous events. As expected, independent biostatisticians analyze unblinded data from ongoing trials for their data-monitoring committees, while trial biostatisticians analyze unblinded data at the end of trials.

Recent advances in safety signal detection methodologies and new guidance requirements provide an opportunity for biostatisticians to aid safety scientists' clinical judgement with quantitative evidence for both ongoing trials and spontaneous reports. Screening blinded data provides an opportunity for biostatisticians to collaborate with their safety scientists in selecting safety topics of interest, background rates and critical values, as well as confidence intervals in a Frequentist framework or probability thresholds in a Bayesian framework. These procedures for detecting safety signals are not decision rules but rather provide an objective trigger for safety scientists to fully assess a safety endpoint. ${ }^{15}$

Another opportunity for biostatisticians is to support benefit-risk assessment, which places safety events in context with the drug's benefits, using qualitative, semi-quantitative and quantitative methods. ${ }^{10}$ Given that a safe drug is not one without risks, but rather one where the benefits outweigh the risks, biostatisticians need to collaborate with a multidisciplinary team to weigh the trade-offs.

Given the different safety analysis as presented in Table 3 , a Bayesian decision approach may prove valuable at key decision points. Goodman used the example of the multidisciplinary FDA advisory panel's discussion of the cardiovascular drug carvedilol. The medical discussion turned from supporting evidence to the interpretation of p-values. Goodman states "the most important contribution of Bayesian methods is the way in which they affect both who participates in a scientific dialogue, and what is discussed. With the emphasis moved from "error rates" to evidence, content experts have an opportunity for their input to be meaningfully incorporated, making it easier for regulatory decisions to be made correctly." 22

Another opportunity is for biostatisticians to collaborate on Program Safety Analysis Plans (PSAPs) proposed by Crowe et al, as well as periodic meta-analyses using the CIOMS's Working Group X guidance. ${ }^{8,14}$ Safety evaluation is a continuum of monitoring, analyzing, and reporting accumulating data, so a plan is essential. ${ }^{23}$ Meta-analyses of accumulating 
Table 3. Who Performs the Various Safety Analyses?

\begin{tabular}{|c|c|c|c|c|c|c|}
\hline Type of Analysis & $\begin{array}{c}\text { Trial } \\
\text { Biostatistician, \% }\end{array}$ & $\begin{array}{c}\text { Independent } \\
\text { Biostatistician, \% }\end{array}$ & $\begin{array}{c}\text { Safety Statistics } \\
\text { Group, \% }\end{array}$ & $\begin{array}{l}\text { Drug Safety } \\
\text { Scientist, \% }\end{array}$ & Epidemiologist, \% & References \\
\hline Unblinded data at end of studies & 100 & 32 & II & 32 & 0 & 4 \\
\hline Investigator brochure & 95 & 16 & II & 37 & II & 1 \\
\hline Meta-analysis of completed studies & 83 & 17 & 17 & 22 & 0 & 8,9 \\
\hline IND submission & 79 & 5 & 5 & 47 & 5 & 2,3 \\
\hline Blinded treatment data of ongoing trials & 67 & 39 & 22 & 44 & 0 & 15,16 \\
\hline Unblinded data of ongoing trials & 21 & 74 & 5 & 26 & 0 & $3,17,18$ \\
\hline Analysis of spontaneous reports & 6 & 6 & II & 100 & II & $|9-2|$ \\
\hline
\end{tabular}

Abbreviation: IND, Investigational New Drug.

Table 4. Who Characterizes Background Rates and What Data Sources Are Used?

\begin{tabular}{lcccccc}
\hline Data Source & Biostatistician, \% & Epidemiologist, \% & Safety Scientist, \% & Clinical Scientist, \% & No One, \% & References \\
\hline Pooled analysis of clinical data & 89 & 17 & 39 & 39 & 0 \\
Meta-analysis of aggregated data & 88 & 24 & 29 & 47 & 3,4 \\
Prior elicitation methodology & 53 & 13 & 7 & 20 & 25 \\
Vital statistics & 31 & 50 & 13 & 77 & 25,26 \\
Literature review & 29 & 59 & 29 & 24 & 0 \\
Public health databases & 24 & 71 & & 27 & 6 \\
\hline
\end{tabular}

data can be used at any time before and after drug approval, for example, in the Integrated Summary of Safety in an NDA or in the Post Marketing Benefit-Risk Evaluation Reports. Given the methodology is quickly evolving, a meta-analysis group of safety scientists, biostatisticians, epidemiologists, and clinicians may be required.

Our survey results indicate that the area least covered by industry biostatisticians is analysis of spontaneous reports. As the statistical separation between pre- and post-approval monitoring diminishes, we will view spontaneous reports not as inferior to trial reports but as having greater uncertainties we must address. ${ }^{19}$

In preparation for working with safety scientists, it is important to use the same safety terminology, which can have subtle differences regarding degree of drug association. CIOMS VI provides a list of terms that define "signal" and distinguish between causality gradients "probably," "possibly," and "likely.", 24

Another opportunity for cross-disciplinary scientific engagement is selecting a treatment comparator or event background rate to put the safety signal into context. Most safety scientists surveyed use background rates found in the literature and provided by key opinion leaders, while biostatisticians use pooled data sources and meta-analysis to estimate rates (Table 4). Biostatisticians also use prior elicitation techniques to estimate background rates, whereby they aggregate multiple opinions into a prior distribution and conduct a Bayesian decision analysis. ${ }^{25}$ This technique is an application of combining medical judgment and quantitative analysis, particularly useful in early-phase studies where data are scarce.

\section{Visual and Analytic Tools}

The attention given to developing and implementing methods for safety analysis is slowly catching up to that given to efficacy analysis. ${ }^{23}$ Yet, many companies have not instituted Program Safety Analysis Plans (PSAPs) and may be unaware of current safety methodologies available in the literature. Now our industry faces the pressure of establishing causality between interventions and adverse events, reducing the volume of less meaningful serious adverse events (SAEs) reporting, and identifying subgroups for risk mitigation and precision medicine. Our survey questions help ascertain what methods are useful in setting and identifying resource priorities.

Survey responses indicate a strong interest to advance in benefit-risk assessment and visualization (Table 5). Benefitrisk methods combine quantitative assessment and clinical judgment to play a role in transparent decision making, and certain methods can be used to determine maximum acceptable risk (as opposed to maximum tolerable risk). ${ }^{49}$ Recent regulatory guidance has provided a decision framework but leaves it to biostatisticians, safety scientists, and regulatory professionals to figure out best implementation practices. ${ }^{11,50}$

Visualization tools have advanced dramatically since the 2008 article "Graphical Approaches to the Analysis of Safety Data From Clinical Trials." 29 Where static graphs have 
Table 5. Importance to Advance in the Following Areas During the Clinical Development Phases.

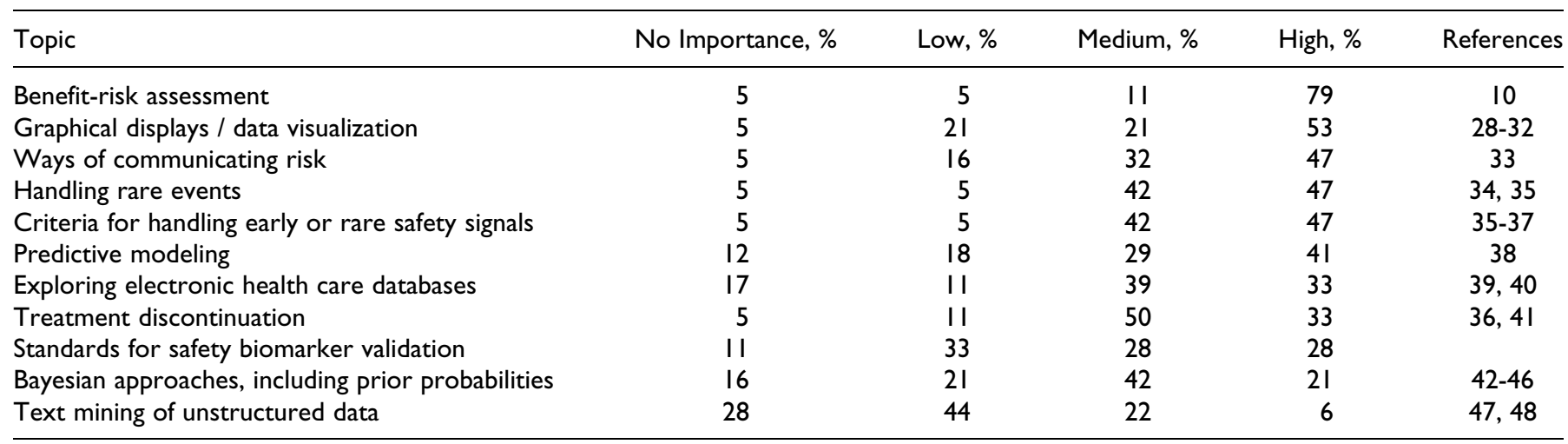

Table 6. Use Static and Interactive Graphical Tools for Safety Monitoring.

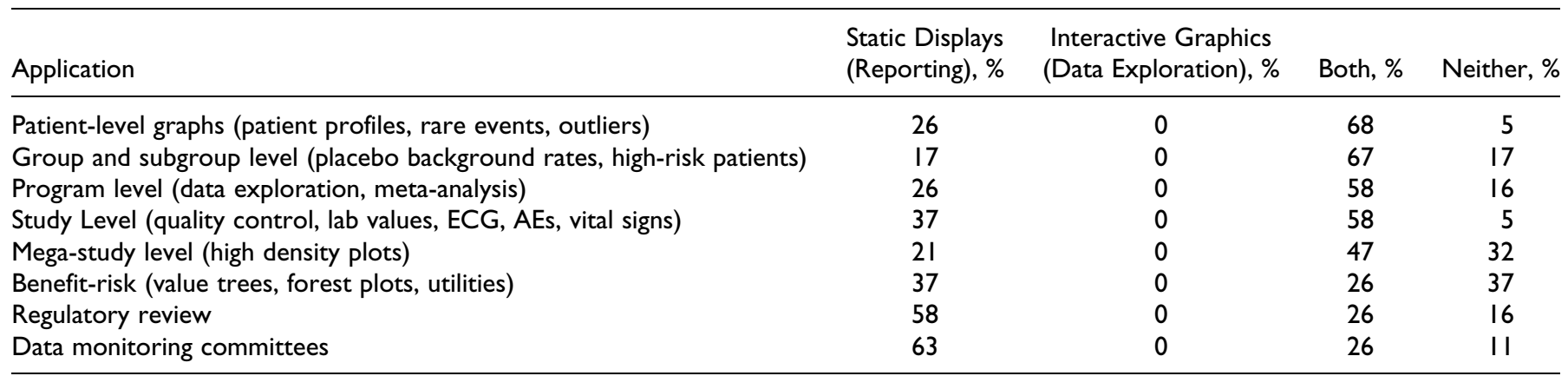

Abbreviations: AEs, adverse events; ECG, electrocardiogram.

Table 7. What Companies Gear Their Statistical Methods for Safety Data Toward.

\begin{tabular}{lrrr}
\hline & Former, \% & Latter, \% & Both, \% \\
\hline Blinded vs unblinded data & 5 & 21 & 74 \\
Study-level vs product-level analysis & 21 & 5 & 74 \\
Patient profiles vs summary statistics & 0 & 32 & 68 \\
Individual vs aggregated studies & 11 & 21 & 68 \\
Tabular vs graphical displays & 42 & 5 & 53 \\
Predictive vs statistical modeling & 11 & 39 & 50 \\
Descriptive vs inferential statistics & 63 & 0 & 37 \\
Qualitative vs quantitative benefit-risk & 58 & 11 & 32 \\
$\quad$ assessment & & & \\
Frequentists vs Bayesian approaches & 79 & 0 & 21 \\
\hline
\end{tabular}

traditionally been used for reporting and publications, interactive visualization is now being used for exploring and monitoring safety data in near real time. ${ }^{51}$ Our survey indicated a wide incorporation of interactive visualization across numerous applications (Table 6). While new point-and-click software has made visualization easier, biostatisticians are still needed to aid in the design of appropriate visualizations and make results unbiased and generalizable. At the very least, biostatisticians, who comprehend probability and uncertainty, can help to effectively communicate risk. ${ }^{52}$ One surprising but not unexpected result concerning the importance of advancement
Table 8. Current Formal Operational Process for Safety Monitoring.

\begin{tabular}{lccrl}
\hline Topic & $\begin{array}{c}\text { Yes, } \\
\%\end{array}$ & $\begin{array}{c}\text { No, But } \\
\text { Planned, } \%\end{array}$ & $\begin{array}{c}\text { No, } \\
\%\end{array}$ & References \\
\hline $\begin{array}{l}\text { Data monitoring committees } \\
\text { Blinded analysis of ongoing trials }\end{array}$ & 94 & 6 & 0 & 54,55 \\
$\begin{array}{l}\text { Unblinded analyses of ongoing } \\
\quad \text { trials }\end{array}$ & 78 & 0 & 22 & 17 \\
$\begin{array}{l}\text { Causality determination } \\
\text { Benefit-risk assessment }\end{array}$ & 74 & 13 & 13 & 36,56 \\
$\begin{array}{l}\text { Program Safety Analysis Plan } \\
\quad \text { PSAP) }\end{array}$ & 64 & 12 & 24 & 14,36 \\
$\begin{array}{l}\text { Interactive graphics } \\
\text { Meta-analyses of completed }\end{array}$ & 52 & 24 & 24 & 51 \\
$\quad$ studies & 44 & 12 & 44 & 8 \\
\hline
\end{tabular}

was the weak interest in Bayesian approaches. This may reflect the past focus on generating safety summary tables at the end of a study. Looking toward the future with aggregating accumulating data, Bayesian approaches can be used to incorporate multiple sources of data and clinical judgment into an analysis. Bayesian posterior probabilities of rare events based on prior beliefs are more informative than Frequentist $P$ values and confidence intervals.

Per Table 7, most companies rely on traditional methods for descriptive statistics, and frequentist approaches. Descriptive 
Table 9. Regulations, Guidance, and Reports That Influence the Quantitative Group's Operations and Deliverables.

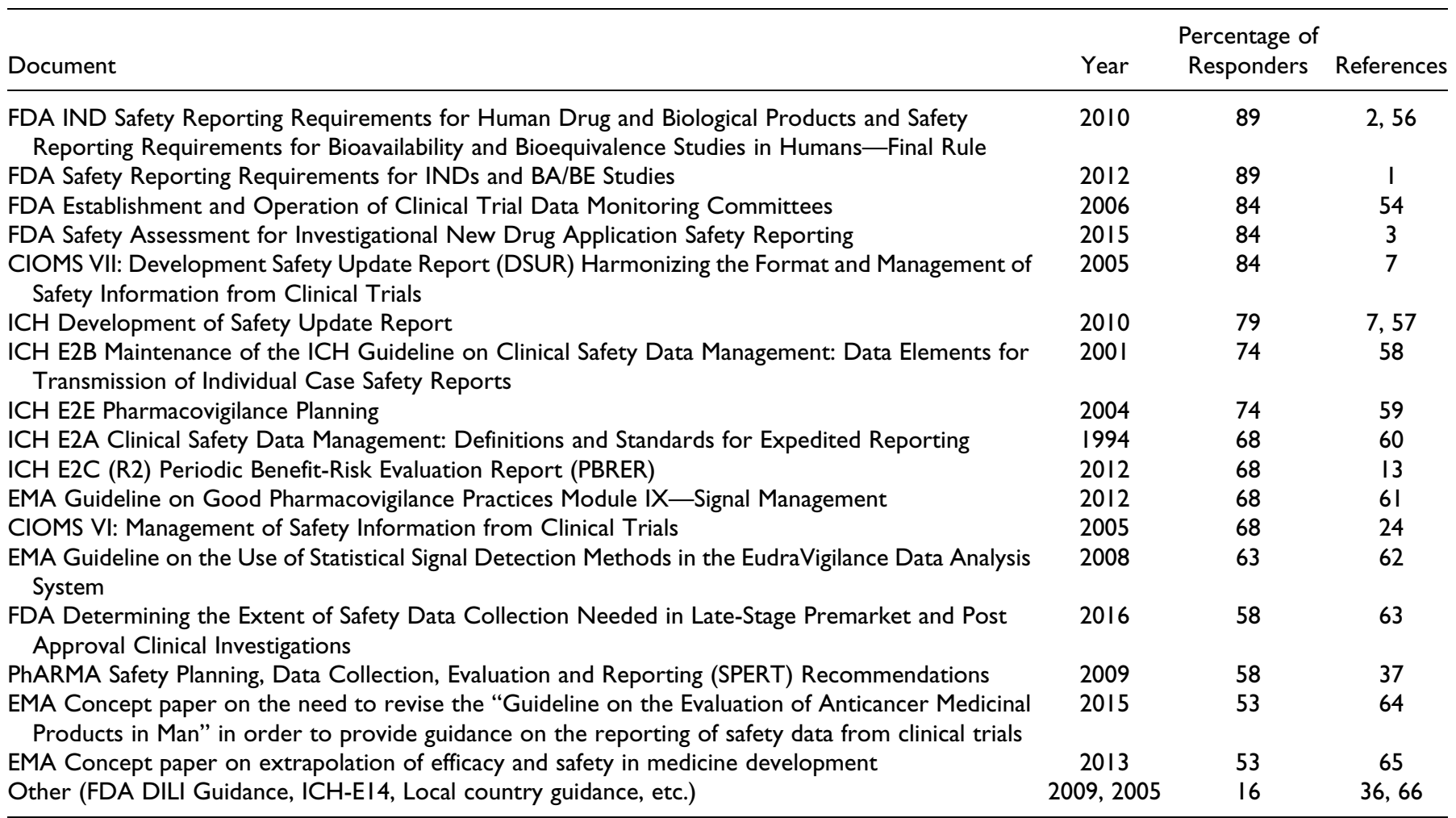

Abbreviations: CIOMS, Council for International Organizations of Medical Sciences; ICH, International Conference on Harmonization; IND, Investigational New Drug.

statistics might have their place with adverse events that are too infrequent for meaningful hypothesis tests or too numerous for controlling Type I error rates. ${ }^{23}$ Use of Bayesian approaches is clearly lagging behind Frequentist approaches. Two areas where Bayesian methods may be advantageous are Bayesian decision making and dynamic monitoring ${ }^{46}$ and safety signal detection. ${ }^{53}$ Biostatisticians can enhance safety monitoring by estimating priors, updating their model parameters as data accrues, and setting signal thresholds for their posterior probabilities.

\section{Effective and Efficient Operational Process}

Biostatisticians typically have processes in place for Data Monitoring Committees and analyses of ongoing trials (blinded or unblinded), but there are opportunities for meta-analysis of completed studies, interactive graphics and Program Safety Analysis Plans (see Table 8). A process for meta-analysis appears to be particularly overlooked but can be guided by the CIOMS X guidance released in December 2016. As expected, processes around newer topics such as interactive graphics and PSAPs are slower to evolve.

A company's operations and deliverables are influenced greatly by the regulatory documents listed in Table 9 . A challenge to biostatisticians is implementing the FDA safety reporting requirements known as the Final Rule. To clarify the Final
Rule, the 2012 final guidance requires sponsors to systematically evaluate accumulating aggregated safety data. Rather than submit every serious adverse event occurring during an active clinical trial, the sponsor needs to determine reasonable possibility of an association with study drug. In December 2015 , more detail was provided requiring that sponsors periodically review accumulating safety data integrated across multiple studies both completed and ongoing and provide a quantitative framework for measuring the evidence of an association between events and study drug. Ball provided a framework for early warning and early stopping of ongoing blinded clinical trials, though it requires biostatisticians and safety scientists to collaborate on designing safety screens with good operating characteristics. ${ }^{15}$ The FDA also recommended broad and frequent unblinding of serious adverse events by a Safety Assessment Committee with analyses prespecified and documented in a Safety Surveillance Plan. The challenge to biostatisticians is how to implement the FDA safety reporting requirements as seamlessly as possible into existing operational activities considering traditional issues such as maintaining blinding and sequestering data.

A biostatistician pursuing safety statistics needs to be familiar with the various regulatory reporting requirements, such as the individual IND safety reports and aggregated PSUR/ PBRER/DSUR. 7,13,57 The DSUR (E2F Development Safety Update Report) covers premarketed drugs, while the PSUR 
(E2C Periodic Safety Update Reports) covers marketed drugs. In 2016 the FDA replaced the PSUR with the PBRER (E2C (R2) Periodic Benefit-Risk Evaluation Report. The PBRER includes benefit as well as safety. For a complete picture of IND reporting, the second and fourth guidance below are good places for biostatisticians to start reading. The fourth guidance recommends having a systematic approach to safety surveillance, including a safety surveillance plan and a safety assessment committee.

Two other informative CIOMS reports not listed in the table above are (a) CIOMS IV: Benefit-Risk Balance for Marketed Drugs: Evaluating Safety Signals ${ }^{12}$ and (b) CIOMS X: "Considerations for applying good meta-analysis practices to clinical safety data within the biopharmaceutical regulatory process. ${ }^{8}$

\section{Discussion}

It is for each company to determine its level of engagement between biostatisticians and safety scientists. Given recent regulations, biostatisticians can significantly contribute to the increased focus on safety during drug development through their inherent skills and expertise understanding and analyzing data. Using the survey above, each company can see how it compares to other companies, and know other companies are advancing in Bayesian approaches, benefit-risk, visualization, etc. The survey can also be used to set priorities for developing expertise, tools, and processes. Recommendations have been given for getting started on the topics most needing to be addressed. By reading the referenced materials, biostatisticians new to the world of drug safety will learn the terminology and issues through the eyes of safety scientists and experts. The next step will be applying existing methods appropriately and developing new methods to use on new types of data. Unlike confirmatory phase 3 efficacy trials, the safety biostatistician will be exploring the data with analytic and visualization tools and using signal detection, meta-analysis, and Bayesian decision analysis on events with uncertain associations, that is, what biostatisticians do best!

\section{Summary}

The Safety Monitoring Working Group representing the Biopharmaceutical Section of the Amercian Statistical Association is providing a development opportunity for its biostatisticians to help safety scientists use quantitative methods to aid their medical judgment and play an important role in ensuring the safety of our patients. We acknowledge that our expertise in well-planned, well-powered efficacy analysis and descriptive safety tables might not always be applicable to safety analysis. However, we believe we have the expertise and skill sets not fully utilized in current safety assessment processes. The working group hopes statisticians will begin with our recommendations based on survey results, so they can better take advantage of more detailed, actionable materials in 2018-2019.

\section{Declaration of Conflicting Interests}

No potential conflicts were declared.

\section{Funding}

No financial support of the research, authorship, and/or publication of this article was declared.

\section{ORCID iD}

Michael W. Colopy, PhD (D https://orcid.org/0000-0002-1806-8818

\section{Supplemental Material}

Supplemental material for this article is available online.

\section{References}

1. US Food and Drug Administration. Guidance for industry and investigators: Safety reporting requirements for INDs and BA/ BE studies. https://www.fda.gov/downloads/Drugs/Guidances/ UCM227351.pdf. Published 2012.

2. US Food and Drug Administration. Final rule, investigational new drug safety reporting requirements for human drug and biologic products and safety reporting requirements for bioavailability and bioequivalence studies in humans. Fed Regist. https://www.gpo. gov/fdsys/pkg/FR-2010-09-29/pdf/2010-24296.pdf. Published September 2010.

3. US Food and Drug Administration. Guidance for industry: safety assessment for IND safety reporting (draft). https://www.fda.gov/ downloads/drugs/guidances/ucm477584.pdf. Published 2015.

4. Chuang-Stein C. Safety analysis in controlled clinical trials. Drug Inform J. 1998;32:1363S-1372S.

5. International Council for Harmonization. M4 S: The CTDSafety, 2001. https://www.fda.gov/downloads/drugs/guidances/ ucm073299.pdf.

6. International Council of Harmonization. Revision of M4E guideline on enhancing the format and structure of benefit-risk information in ICH efficacy-M4E(R2). http://www.ich.org/ fileadmin/Public_Web_Site/ICH_Products/CTD/M4E_R2_Effi cacy/M4E_R2_Step_4.pdf. Published 2016.

7. Council for International Organizations of Medical Sciences (CIOMS) Working Group VII. Development Safety Update Report (DSUR) harmonizing the format and content for periodic safety report during clinical trials, Geneva, Switzerland, 2006. https://cioms.ch/shop/product/development-safety-update-reportdsur-harmonizing-the-format-and-content-for-periodic-safetyreport-during-clinical-trials-report-of-cioms-working-group-vii/.

8. Council for International Organizations of Medical Sciences (CIOMS), Report of CIOMS Working Group X. Evidence Synthesis and Meta-analysis for Drug Safety. Geneva, Switzerland: WHO Press; 2016.

9. European Medicines Agency. Points to consider on application with 1. Meta-Analysis; 2. One Pivotal Study. CPMP/EWP/2330/ 99. London, 31 May 2001. http://www.ema.europa.eu/docs/en_ GB/document_library/Scientific_guideline/2009/09/WC500003 657.pdf. 
10. Jiang Q, He W. Benefit-Risk Assessment Methods in Medicinal Product Development: Bridging Qualitative and Quantitative Assessments. Boca Raton, FL: Chapman \& Hall / CRC Press; 2016.

11. IMI PROTECT. Benefit-risk assessment and communication: a case study of natalizumab and PML, 2013. http://www.imi-protec t.eu/documents/AshbyDBenefit-riskassessmentandcommunicatio nICPEMontreal26-29August2013.pdf.

12. Council for International Organizations of Medical Sciences (CIOMS) Working Group IV. Benefit-risk balance for marketed drugs: evaluating safety signals, Geneva, Switzerland, 1998. https://cioms.ch/wp-content/uploads/2017/01/benefit-risk.pdf.

13. US Food and Drug Administration. Guidance for industry: E2C(R2) Periodic Benefit Risk Evaluation Report (PBRER) Guidance for Industry. https://www.fda.gov/downloads/drugs/gui dances/ucm299513.pdf. Published July 2016.

14. Crowe B, Xia HA, Nilsson M, Shahin S, Wang W, Jiang Q. Program safety analysis plan: an implementation guide. In: Jiang Q, Xia HA, eds. Quantitative Evaluation of Safety in Drug Development: Design, Analysis and Reporting. Boca Raton, FL: Chapman \& Hall/CRC Biostatistics Series; 2015:55-68.

15. Ball G.Continuous safety monitoring for randomized controlled clinical trials with blinded treatment information Part 4: One method. Contemp Clin Trials. 2011;32:S11-S17.

16. O'Neill RT. Statistical concepts in the planning and evaluation of drug safety from clinical trials in drug development: issues on international harmonization. Stat Med. 1995;14:1117-1127.

17. Yao B, Zhu L, Jiang Q, Xia HA. Safety monitoring in clinical trials. Pharmaceutics. 2013;5:94-106.

18. International Council of Harmonization. E6 Version R2: good clinical practice guidelines. http://www.ich.org. Published 2016. Accessed April 23, 2017.

19. Gould AL, Lystig TC, Lu Y, Fu H, Ma H. Methods and issues to consider for detection of safety signals from spontaneous reporting databases: a report of the DIA Bayesian Safety Signal Detection Working Group. Therapeutic Innovation \& Regulatory Science. 2015;49:65-75.

20. Clark JA, Klincewicz SL, Stang PE. Spontaneous adverse event signaling methods: classification and use with health care treatment products. Epidemiol Rev. 2001;23:191-210.

21. Chuang-Stein C, Le V. Recent advancements in the analysis and presentation of safety data. Drug Inform J. 2001;35:377-397.

22. Goodman SN. Introduction to Bayesian methods I: measuring the strength of evidence. Clin Trials. 2005;2:282-290.

23. Chuang-Stein C, Xia HA. The practice of pre-marketing safety assessment in drug development. J Biopharm Stat. 2013;23:3-25.

24. Council for International Organizations of Medical Sciences (CIOMS) Working Group VI. Management of Safety Information From Clinical Trials. Geneva, Switzerland. https://cioms.ch/ shop/product/management-of-safety-information-from-clinicaltrialsreport-of-cioms-working-group-vi/. Published 2005.

25. O'Hagan A. Uncertain Judgements: Elicitating Experts' Probabilities. Chichester, UK: Wiley; 2006.

26. Chaloner K, Rhame F. Quantifying and documenting prior beliefs in clinical trials. Stat Med. 2001;20:581-600.
27. US Food and Drug Administration. Guidance for industry: good pharmacovigilance practices and pharmacoepidemiologic assessment, 2005. https://www.fda.gov/downloads/drugs/guidancecom plianceregulatoryinformation/guidances/ucm071696.pdf.

28. Hallgreen CE, Mt-Isa S, Lieftucht A, et al; on behalf of PROTECT Benefit-Risk Group. Literature review of visual representation of the results of benefit-risk assessments of medicinal products. Pharmacoepidemiol Drug Saf. 2016;25:238-250.

29. Amit O, Heiberger RM, Lane PW. Graphical approaches to the analysis of safety data from clinical trials. Pharm Stat. 2008;7: 20-35.

30. National CTSA Consortium. CTSPedia Clinical Trials Safety Graphics. https://www.ctspedia.org/do/view/CTSpedia/ StatGraphHome.

31. Gould L. Safety graphics. In: Gould AL, ed. Statistical Methods for Evaluating Safety in Medical Product Development. Chichester, UK: Wiley; 2015:22-65.

32. Wen S, He W, Evans S, et al. Visualization of benefit-risk assessment in medical products with real examples. In: Jiang Q, He W, eds. Benefit-Risk Assessment Methods in Medical Product Development. Boca Raton, FL: Chapman \& Hall/CRC Biostatistics Series; 2016:197-231.

33. European Medicines Agency. Benefit-risk methodology project report on risk perception study module. http://www.ema.euro pa.eu/docs/en_GB/document_library/Report/2012/02/ WC500123226.pdf. Published 2012.

34. Southworth H, Hernan JE. Extreme value modelling of laboratory safety data from clinical studies. Pharm Stat. 2012;11:361-366.

35. Williams R. Analyzing rare events with logistic regression. https://www3.nd.edu/ rwilliam/stats3/RareEvents.pdf. Published April 7, 2017.

36. US Food and Drug Administration. Guidance for industry: drug induced liver injury: premarketing clinical evaluation. https:// www.fda.gov/downloads/Drugs//guidances/UCM174090.pdf. Published 2009.

37. Crowe BJ, Xia HA, Berlin JA, Watson DJ, et al. Recommendations for safety planning, data collection, evaluation and reporting during drug, biologic and vaccine development: a report of the safety planning, evaluation, and reporting team. Clin Trials. 2009; 6:430-440.

38. Southworth H. Predicting potential liver toxicity from phase 2 data: a case study with ximelagatran. Stat Med. 2014;33: 2914-2923.

39. Harrell F. Exploratory analysis of clinical safety data to detect safety signals. http://biostat.mc.vanderbilt.edu/wiki/pub/Main/ FHHandouts/gsksafety.pdf. Published 2005.

40. Bate A, Lindquist M, Edwards R, Orre R. A data mining approach for signal detection and analysis. Drug Saf. 2002;25:393-397.

41. Vermeer NS, Straus S, Mantel-Teeuwisse AK, et al. Druginduced progressive multifocal leukoencephalopathy: lessons learned from contrasting natalizumab and rituximab. Clin Pharmacol Ther. 2015;98:542-550.

42. Lanctot KL, Naranjo CA. Comparison of the Bayesian approach and a simple algorithm for assessment of adverse drug events. Clin Pharmacol Ther. 1995;58:692-698. 
43. Kramer MS. A Bayesian approach to assessment of adverse drug reactions: evaluation of a case of fatal anaphylaxis. Drug Inf J. 1986;20:505-517.

44. Xia HA, Jiang Q. Statistical evaluation of drug safety data. Therapeutic Innovation \& Regulatory Science. 2014;48:109-120.

45. Jiang Q, Xia HA, eds. Quantitative Evaluation of Safety in Drug Development: Design, Analysis and Reporting. Boca Raton, FL: CRC Press; 2015.

46. Spiegelhalter D, Abrams K, Myles P, eds. Bayesian Approaches to Clinical Trials and Health Care Evaluation. Chichester, UK: Wiley \& Sons Ltd; 2004.

47. Wilson AM, Thabane L, Holbrook A. Application of data mining techniques in pharmacovigilance. Br J Clin Pharmacol. 2003;57: 127-134.

48. Sarker A, Ginn R, Nikfarjam A, et al. Utilizing social media data for pharmacovigilance: a review. J Biomed Inform. 2015;54:202-212.

49. Hauber AB, Johnson FR, Andrews EB. Risk-benefit analysis methods for pharmaceutical decision-making - where are we now? ISPOR Connections, 2016. https://www.ispor.org/news/arti cles/dec06/riskbenefitsanalysis.asp.

50. Noel R.Benefit-risk assessment in drug development: progress to date and future directions. Public Meeting on Benefit-Risk Assessments in Drug Regulatory Decision-Making, September 18, 2017. https://www.fda.gov/downloads/ForIndustry/UserFees/ PrescriptionDrugUserFee/UCM576722.pdf.

51. Southworth H. Efficient and effective review of clinical trial safety data using interactive graphics and tables. In: Krause A, O'Connell M, eds. A Picture Is Worth a Thousand Words: Graphics in Life Sciences. New York, NY: Springer; 2012: 199-216.

52. Fischhoff B, Noel T, Brewer NT, Julie S, Downs JS, eds. Communicating risks and benefits: an evidence-based user's guide. US Food and Drug Administration. Published August 2011. https:// www.fda.gov/downloads/AboutFDA/ReportsManualsForms/ Reports/UCM268069.pdf.

53. Fries M, Kracht K, Li J, et al. Safety monitoring methodology in the premarketing setting. JSM Proc. 2016:2247-2269. https:// ww2.amstat.org/MembersOnly/proceedings/2016/data/assets/ pdf/389675.pdf.

54. US Food and Drug Administration. Guidance for clinical trial sponsors: establishment and operation of clinical trial data monitoring committees. https://www.fda.gov/downloads/Regulatory Information/Guidances/ucm127073.pdf. Published 2006.

55. Herson J. Safety monitoring. In: Gould AL Medical Product Development. Chichester, UK: Wiley; 2015:293-318.

56. Wittes J, Crowe B, Chuang-Stein C, et al. The FDA's final rule on expedited safety reporting: statistical considerations. Stat Biopharm Res. 2015;7:174-190.
57. International Conference on Harmonization. E2F development safety update report. http://www.ich.org/fileadmin/Public_Web_ Site/ICH_Products/Guidelines/Efficacy/E2F/Step4/E2F_Step_ 4.pdf. Published 2010.

58. International Conference on Harmonization. E2B(R2) Maintenance of the ICH guideline on clinical safety data management: data elements for transmission of individual case safety reports, 2001. https://www.fda.gov/downloads/Drugs/ GuidanceComplianceRegulatoryInformation/Guidances/ UCM275638.pdf.

59. US Food and Drug Administration. Guidance for industry: E2E pharmacovigilance planning. https://www.fda.gov/downloads/ Drugs/GuidanceComplianceRegulatoryInformation/Guidances/ UCM073107.pdf. Published 2005.

60. International Conference on Harmonization. E2A clinical safety data management: definitions and standards for expedited reporting. https://www.ich.org/fileadmin/Public_Web_Site/ICH_ Products/Guidelines/Efficacy/E2A/Step4/E2A_Guideline.pdf. Published 1994.

61. European Medicines Agency. Guideline on good pharmacovigilance practices (GVP) Module IX-signal management. http://www.ema.europa.eu/docs/en_GB/document_library/ Scientific_guideline/2017/10/WC500236408.pdf. Published 2015.

62. European Medicines Agency. Guideline on the use of statistical signal detection methods in the EudraVigilance data analysis system, 2008. http://www.ema.europa.eu/docs/en_GB/document_ library/Regulatory_and_procedural_guideline/2009/11/ WC500011434.pdf.

63. US Food and Drug Administration. Guidance for industry: determining the extent of safety data collection needed in late-stage premarket and postapproval clinical investigations. https:// www.fda.gov/downloads/drugs/guidances/ucm291158.pdf. Published February 2016.

64. European Medicines Agency. Concept paper on the need to revise condition-specific guidance, Appendix 4 to the guideline on the evaluation of anticancer medicinal products in man, 2017. http:// www.ema.europa.eu/docs/en_GB/document_library/Scientific_ guideline/2017/03/WC500224997.pdf.

65. European Medicines Agency. Concept paper on extrapolation of efficacy and safety in medicine development, 2013. http:/www.e ma.europa.eu/docs/en_GB/document_library/Scientific_guide line/2013/04/WC500142358.pdf.

66. Food and Drug Administration. Guidance for industry: E14 clinical evaluation of QT/QTc interval prolongation and proarrhythmic potential for non-antiarrhythmic drugs. http://www.fda.gov/ downloads/RegulatoryInformation/Guidances/ucm129357.pdf. Published 2005. 